\title{
Measuring military university students' motivational goals in the domain of physical exercise
}

DOI 10.1515/jms-2016-0001

Received December 10, 2015; accepted April 22, 2016

\begin{abstract}
The aim of this study was to test whether the existing achievement goal orientation instrument could be modified to measure goal endorsement in recreational physical training. The participants were 139 second-year students at the Finnish National Defense University. The orientations were assessed using a modified questionnaire that included four orientations: mastery-intrinsic orientation (focus on learning new things and developing competence), mastery-extrinsic orientation (focus on learning and mastery but with extrinsic criteria such as grades), performance-approach orientation (focus on outperforming others) and performance-avoidance orientation (focus on avoiding judgments of incompetence). Based on the exploratory and confirmatory factor analyses, factor structures were compared. The comparison of psychometric results of different models supported the four-dimensional instrument. The participants mostly strived for personal development of fitness, as well as good results. They also emphasized social comparison to some extent but had very little concerns of failure or appearing inferior.
\end{abstract}

Keywords: motivation, physical training, achievement goal orientation, exploratory factor analysis, confirmatory factor analysis

*Corresponding author: Antti-Tuomas Pulkka, Department of Leadership and Military Pedagogy, National Defence University, Helsinki, Finland, E-mail: antti-tuomas.pulkka@mil.fi

\section{Introduction}

Research on motivational goals, in terms of studies on achievement goals and goal orientations (for reviews, refer Urdan 1997; Pintrich 2003; Maehr and Zusho 2009; Wigfield and Cambria 2010), focuses on learners' reasons for engaging in achievement-related situations. Such goal preferences are related to learning, affect and other educationally relevant outcomes (e.g. Kaplan and Maehr 2007).

Originally, achievement goal research focused on the goals that students prefer in performance situations (Dweck and Elliot 1983) or the motivational states induced in students (Nicholls 1984). In early research, a differentiation was made between (i) motivational strivings related to mastery or learning (e.g. learning goals or task involvement) with the purpose of increasing competence and (ii) relative performance (e.g. performance goals or ego involvement) with the purpose of displaying competence. Later research has complemented this original two-dimensional conceptualization, extended to domains of work (e.g. Button et al. 1996; Vandewalle 1997) and sports (e.g. Duda and Nicholls 1992; Duda 1994; Duda and Whitehead 1998; Papaioannou et al. 2012), and provided rich knowledge about the correlations and consequences of achievement goal preferences. In general, goal preferences regulate and direct an individual's behaviour, affect and learning in relation to achievement situations.

In terms of the terminology and the different lines of research, achievement goal preferences are often studied situationally or specifically defined or induced contextually. Consequently, such preferences, through repeated exposure to achievement situations, generalize to form an integral part of individuals' motivational tendencies. This function was discussed by Nicholls (1989) as motivational orientations and by Dweck (1992) as higher-order purpose goals. Thus, achievement goals refer to end states that reflect what students strive for situationally, but achievement goal orientations represent generalized tendencies to prefer 
certain types of goals (see Urdan 1997; Niemivirta 2002; Kaplan and Maehr 2007). Extending from educational settings, achievement goal preferences have also been examined in relation to social cognitive models of motivation in sports (cf. Duda and Whitehead 1998). Examination of motivational goals in physical training is important, as different forms of goal preferences are related to generally relevant outcomes, e.g. perceived purposes of sport (Duda 1989) and enjoyment of exercise (Kilpatrick et al. 2003; for review, refer Papaioannou et al. 2012).

It seems that many prior questionnaires have been designed to tap goal endorsement in contexts of physical education classes or competitive sports, conducted with samples of children or adolescents (e.g. Wang et al. 2007; Shen et al. 2009). The goal of this study was to modify the existing achievement goal orientation instrument to measure preferences of goals in terms that are relevant to one's physical training and with a distinction from professional athletic activities or explicit competition. The extension, here, is then from prior research by examining goal orientations in a young adult population in terms of recreational, personal physical exercise. In this context, the current study moves forward from one field of achievement-related situations to another, but also to a more domain-specific level of goal preferences. Moreover, it has been noted that the structure of achievement goal dimensions in the physical field may vary across different target groups (Chi and Duda 1995). It follows that measurement of goal preferences with adapted items should include careful assessment of the observed structure in relation to expected dimensions.

\subsection{Dimensions of achievement goal orientations}

The original partition of two dimensions (learning vs. performance), which were considered relatively opposing, has been refined by the identification of more-specified dimensions and a point of view that recognizes simultaneous emphasis of multiple goals (Pintrich 2000, 2003; Elliot 2005; Kaplan and Maehr 2007). More in-depth reviews of goal research have been conducted and reported elsewhere (e.g. Urdan 1997; Vandewalle 1997; Duda and Whitehead 1998; Jagacinski and Duda 2001; Hulleman et al. 2010); in this article, my purpose is to focus on instrumentation that draws from and illustrates the same theoretical and empirical backgrounds of achievement goal research. Achievement goals have been labelled and operationalized in varying ways in prior studies, but as the two 'primary orientations' accentuate similar key contents in generic terms (cf. Ames and Archer 1987, 1988; Elliot 2005), these dimensions are referred to as mastery and performance goals or goal orientations in this study (except when citing the original terms becomes necessary).

First, in chronological order, two types of performance strivings were distinguished: focus on performanceapproach and performance-avoidance goals (the so-called trichotomous model; cf. Elliot and Harackiewicz 1996; Middleton and Midgley 1997; also refer Skaalvik 1997). Performance-approach goals include demonstrating competence and outperforming others, while the performance-avoidance goals refer to avoiding failure or verdicts of unskilfulness.

Second, in addition to mastery goals, which refer to the learning focus (learning goals or task involvement; cf. Nicholls 1984; Dweck 1986), an additional class of mastery-avoidance goals has been proposed. This dimension defines competence in absolute/intrapersonal terms, but which is negatively valenced ( $2 \times 2$ model; refer Elliot and McGregor 2001). ${ }^{1}$ Another recent elaboration of learning focus is the mastery-extrinsic goal orientation concept, which refers to an emphasis on competence development that is evaluated based on external criteria, such as grades at school (Niemivirta 2002; also refer Grant and Dweck 2003: outcome goals). Thus, distinct from mastery-intrinsic orientation, which includes self-set criteria, mastery-extrinsic orientation refers to extrinsic criteria but similarly with intrapersonal standards for learning or improvement. Grading is a general practice in educational contexts, and thus, students quite frequently interpret grades as a criterion for learning without reference to social comparison. In other words, some students associate high academic achievement to mastery regardless of other students' performance. It follows that mastery-extrinsic orientation depicts an emphasis of grades or formal results in general as a criterion of personal proficiency or competence. This personal competence is, in a sense, learning and achievement (with an absolute connotation) in educational contexts, and, as I postulate in the current study, personal development in the domain of personal physical exercise. Prior studies have also identified the construct validity, differentiation and explanatory power of the mastery-extrinsic orientation construct. Supportive evidence demonstrates

1 Recently, it has been suggested that achievement strivings could be conceptualized based on three standards of competence references (task, self and other), valenced in terms of approach and avoidance tendencies (3×2 model; refer Elliot et al. 2011). 
distinctive patterns of relations with other motivational variables and with variables linked to students' emotional subjective well-being (Tuominen-Soini et al. 2008, 2011, 2012; Tapola et al. 2013, 2014).

Different achievement goal dimensions have also been applied in motivational research in the field of sports and physical education. Following the work of goal orientation theorists, Duda (1992) proposed that people have motivational tendencies also related to sports in terms of dispositional task and ego goal emphasis. Duda and Whitehead (1998: 22) referred to these goal categories as distinct ways in which people process certain activity. Different perspectives and contexts have led to varied definitions and operationalizations, as well as a variety of labels (Duda and Whitehead 1998: 23). Altogether, Nicholls and Duda (cf. Duda and Nicholls 1992) modified an instrument measuring dispositional goals in classroom settings so that it could be applied in a sports context. In this most significant work, Duda and Nicholls (1992) differentiated between the two original goal dimensions, i.e. task and ego, in Nicholls' terms. The trichotomous model of achievement goals has also been examined in the physical field. For example, Shen et al. have used adapted measures into contexts of softball and physical education classes. Their studies have shown that the proposed dimensions (mastery, performance-approach and performance-avoidance), after being adapted to the physical context, were structurally identical to the original scales (Shen et al. 2007; Shen et al. 2009). Later on, Wang et al. implemented the $2 \times 2$ achievement goal framework to examine adolescents' motivation in physical education classes. Their results supported the hypothesized four-factor structure consisting of mastery-approach, performance-approach, mastery-avoidance and performance-avoidance goals (Wang et al. 2007).

\subsection{Current study}

In this study, I follow the works of Nicholls et al. in the conceptualization of dispositional goal orientations (Nicholls 1989; Nicholls et al. 1989) and aim to extend prior research by examining adult students' motivation in physical exercise using contemporary instrumentation.

To start with, it seems that mostly prior instrumentations are focused on, and thus limited in, context and terms related to competitive sports or to young peoples' experiences in physical education in school. As is discussed in Duda and Whitehead (1998), the reference of success in competitive sports is anchored to the concept of winning. With regard to classroom or the class context in school, a person's goal endorsement is reflected in his/ her stance in relation to evaluation practices and pedagogical delivery (e.g. Ames 1992). In recreational sport or individuals' physical training, goal structures need to be differently anchored or referenced than in competitive sports or classroom work. In practice, it is necessary to express items in terms that are relevant to how adults approach their personal physical exercise.

This study adopts the operationalization of personal achievement goal orientations, proposed by Niemivirta (2002), as the baseline. ${ }^{2}$ Following this, first, the mastery or learning dimension is clarified in a sense that enables mastery to be pursued with distinct criteria. Hence, distinction is made between mastery-intrinsic and mastery-extrinsic goal preferences (Niemivirta 2002). Mastery-intrinsic goal orientation depicts the traditional operationalization of a focus on mastery strivings (i.e. mastery/learning goals or task involvement; cf. Nicholls 1984; Ames 1992; Dweck 1992), whereby the criteria for evaluating the attainment of mastery are intrinsic (e.g. personal experience or evaluation of development and learning). Instead, the emphasis of mastery-extrinsic goal orientation refers to a reliance on more extrinsic criteria for learning or improved competence (e.g. good grades, absolute success or positive feedback) (Niemivirta 2002; also refer Grant and Dweck 2003).

Second, two types of performance goal strivings are distinguished: (a) performance-approach and (b) performance-avoidance orientations (e.g. Elliot and Harackiewicz 1996; Middleton and Midgley 1997; also self-enhancing and self-defeating ego orientations, as in Skaalvik 1997). The performance-approach orientation reflects the aim of demonstrating competence or appearing better than others, while the performance-avoidance orientation has a focus on avoiding judgments of incompetence or appearing worse than others.

2 The original instrumentation also includes a fifth dimension, work avoidance orientation, which includes aims of avoiding effort and evading challenges, instead of striving for competence or any specific relevant outcomes. This scale was omitted as the very idea of avoiding effort is not relevant to the context of physical exercise; if one was only trying to avoid input of effort, one would altogether avoid exercise. Perhaps the concept of avoidance in this context could be addressed by examining some sort of levels of effort one is willing to input for certain levels of outcomes: this remains to be examined in future research. The idea and different wordings for adaptation were initially tried out in Visa Eloranta's Bachelor's Thesis (National Defence University, Helsinki, Finland; 2015), but the adaptation of items and the data of this study are independent from his work. 


\section{Methods}

\subsection{Participants}

The participants comprised 139 (aged 20-23 years) second-year students at the Finnish National Defense University (NDU). In Finland, higher education in military science is provided by the NDU, which trains officers for the Finnish Defence Forces. The military students are recruited after they have completed their military service, which is obligatory for Finnish men (conscription) and voluntary for Finnish women. The annual intake of the NDU is approximately 140 and only $3 \%-6 \%$ of the students were female at the time the measurements of this study were conducted. The selection process consists of a preselection phase based on applications, prior education and military service records, followed by a series of psychological and ability tests, as well as physiological screening. Undergraduate studies (Bachelor of Military Science) last 3 years and include a combination of academic and vocational studies. Part of their training is, naturally, very physical and students need to complete certain fitness tests during their studies in order to graduate.

\subsection{Measures}

Achievement goal orientations were assessed using a modified questionnaire (Niemivirta 2002; also refer Tuominen-Soini et al. 2012; Pulkka and Niemivirta 2013; Tapola et al. 2014, for studies that have used the original instrument in Finnish), which in this study included four types of orientations: mastery-intrinsic (focus on learning new things and developing competence), mastery-extrinsic (focus on learning and mastery but with extrinsic criteria such as grades), performance-approach (focus on outperforming others) and performance-avoidance orientation (focus on avoiding judgments of incompetence).

The adaptation of the instrument included revising the wording of original items by replacing anchor terms such as 'studies' and 'school' with, e.g. 'when I exercise' or 'in physical training' and so on. Furthermore, the criterion, reference or projected outcome was modified from, e.g. 'grades' to 'results', appearing 'competent' into 'fit' and so on. Following this, the initial instrument included altogether 12 items for the chosen four goal orientation dimensions: mastery-intrinsic orientation (three items, e.g. 'I train to improve and develop my fitness level.'), mastery-extrinsic orientation (three items, e.g. 'Getting good results is important for me.'), performance-approach orientation (three items, e.g. 'An important goal for me when I exercise is to do better than other people.') and performance-avoidance orientation (three items, e.g. 'It is important for me not to fail in front of other people when I exercise.'). The paper-and-pencil questionnaire (in Finnish) was administered to the students by the author himself. Students were informed of the purposes of the study, on data handling procedures as well as on anonymity, and they were instructed to leave an item unanswered if they did not understand it or found that they could not answer it. Cadets rated each statement on a Likert scale ranging from 1 (not true at all) to 7 (very true).

\subsection{Data analysis}

As this study applies the existing instrument to a significantly different field of achievement, and to a more domain-specific level, thorough examination of the structure is deemed necessary. Following analytical strategies that have been used in the validation of a new instrument (e.g. Vandewalle 1997) and research on dimensionality of achievement goal orientations (e.g. Zweig and Webster 2004; Attenweiler and Moore 2006), the following procedure was implemented. A series of explorative maximum-likelihood factor analyses with varimax rotation, as implemented in SPSS 23, was conducted for all items, and item analyses were used to examine the consistency of the resulting scales. The structural validity was tested with confirmatory factor analysis with Mplus Statistics software (Muthén and Muthén 1998-2009). Thus, the analytical strategy was to extract a plausible solution and to compare it with theoretical suggestions as well as fit to data.

\section{Results}

\subsection{Exploratory factor analyses}

A series of factor analyses indicated that, initially, the resulting structure deviated to some extent from the proposed dimensions, and that several parallel paths of iterations were plausible. Factors were extracted for each model based on inspection of the factor structure and the contents of items. Results from the Kaiser-Meyer-Olkin Measure of Sampling Adequacy and Bartlett's test of sphericity indicated that the data matrix was appropriate for factor analysis. 
After excluding one item from the performanceapproach orientation, based on slightly low communality, the initial solution suggested two factors, of which the first included items from the mastery-intrinsic and mastery-extrinsic scales. This factor reflected striving for good results and optimal development. The second factor included items on performance-avoidance orientation and performance-approach scales. This factor reflected striving to outperform others and avoiding appearing less fit or less able than others. Altogether, this solution, which included 11 of the original 12 items, suggested two combined mastery and performance dimensions. Item analysis showed that the internal consistency of the proposed scales was good. However, the goodness-of-fit test indicated that the structure was significantly dissimilar to the data $(p<0.001)$. This solution is labelled as two-dimensional for comparison.

As the aim of this study was to explore the dimensionality of goal preferences in physical training, theoretically grounded compositions and reasonable modifications were examined.

First, it was deemed necessary to examine whether the inclusion of the rather novel (in this context) mastery-extrinsic orientation caused the unexpected structural results via its close relation to mastery-intrinsic orientation. Thus, it was tested whether the trichotomous model could be observed in the data. A factor analysis that was conducted on only nine items from mastery-intrinsic, performance-approach and performance-avoidance orientations yielded precisely the expected three dimensions, with only some slight crossloading, for two items, between performance-approach- and performance-avoidance-focused factors. Goodness-of-fit test $(p=0.123)$ indicated that the solution was not significantly different from the data. Item analysis showed that the internal consistency of the proposed scales was good for the first two factors but only moderate (0.68) for the third factor, which included the performance-approach items. This solution is labelled as three-dimensional for further analysis.

Second, a forced four-factor model was examined. Following the former model, items theoretically pertaining to the mastery-extrinsic orientation were added. The rationale for this was to find out whether the implemented partition would produce two independent factors for the two mastery-focused orientations. The extracted four factors each included the original corresponding items of the proposed four dimensions - with the exception of one item from the mastery-intrinsic orientation ('To develop as much as possible is an important goal for me in my training.') loaded into the factor that included all mastery-extrinsic items. Based on the item analyses, and for the purposes of clarity, this item was excluded from further analysis. It may be that the actual wording of the item 'as much as possible' is associated more with external criteria than simply 'personal best', which was the intention behind this item. This modified solution yielded four factors that included items from the original corresponding scales. Goodness-of-fit test $(p=0.166)$ indicated that the solution was not significantly different from the data. Item analysis showed that the internal consistency of the proposed scales was good. This solution is labelled reduced four-dimensional for further analysis.

Factor loadings, corresponding items and statistics from the item analysis for these three factor solutions are reported in Table 1.

Tab. 1: Factor loadings, internal consistencies and corrected item-total correlations for parallel solutions.

\begin{tabular}{|c|c|c|c|c|}
\hline \multirow[t]{2}{*}{ Factor } & \multicolumn{4}{|l|}{ Item } \\
\hline & $\alpha$ & $\lambda$ & $r_{\text {cit }}$ & Original scale \\
\hline \multicolumn{5}{|c|}{ Two-dimensional model ( $58.1 \%$ of variance explained), goodness-of-fit $x^{2} / d f=160.3 / 34, p<0.001$} \\
\hline Factor 1 & 0.89 & & & \\
\hline 26. To develop as much as possible is an important goal for me in my training. & & 0.85 & 0.75 & Mast-int \\
\hline 4. An important goal for me is to get good results in sports. & & 0.84 & 0.78 & Mast-ext \\
\hline 28. Getting good results is important for me. & & 0.82 & 0.74 & Mast-ext \\
\hline 34. My goal is to do well in training. & & 0.79 & 0.73 & Mast-ext \\
\hline 11. I train to improve and develop my fitness level. & & 0.72 & 0.68 & Mast-int \\
\hline 17. To develop is an important goal for me in my training. & & 0.64 & 0.60 & Mast-int \\
\hline Factor 2 & 0.81 & & & \\
\hline 24. It is important for me not to fail in front of other people when I exercise. & & 0.82 & 0.72 & Perf-avo \\
\hline 9. I try to avoid situations in training in which I might look less fit or weak. & & 0.82 & 0.65 & Perf-avo \\
\hline 16. I try to avoid situations in training in which I might fail or make mistakes. & & 0.82 & 0.64 & Perf-avo \\
\hline 29. It is important for me that others think that I am competent and fit. & & 0.50 & 0.52 & Perf-appr \\
\hline 22. It feels really good if I manage to show others that I am really fit. & & 0.48 & 0.50 & Perf-appr \\
\hline
\end{tabular}


Tab. 1: (continued)

\begin{tabular}{|c|c|c|c|c|}
\hline \multirow[t]{2}{*}{ Factor } & \multicolumn{4}{|l|}{ Item } \\
\hline & $\alpha$ & $\lambda$ & $r_{\text {cit }}$ & Original scale \\
\hline \multicolumn{5}{|c|}{ Three-dimensional model ( $64.6 \%$ of variance explained), goodness-of-fit $x^{2} / d f=16.6 / 12, p=0.166$} \\
\hline Factor 1 & 0.87 & & & \\
\hline 16. I try to avoid situations in training in which I might fail or make mistakes. & & 0.89 & 0.77 & Perf-avo \\
\hline 9. I try to avoid situations in training in which I might look less fit or weak. & & 0.79 & 0.75 & Perf-avo \\
\hline 24. It is important for me not to fail in front of other people when I exercise. & & 0.75 & 0.71 & Perf-avo \\
\hline Factor 2 & 0.81 & & & \\
\hline 11. I train to improve and develop my fitness level. & & 0.91 & 0.76 & Mast-int \\
\hline 17. To develop is an important goal for me in my training. & & 0.87 & 0.73 & Mast-int \\
\hline 26. To develop as much as possible is an important goal for me in my training. & & 0.65 & 0.58 & Mast-int \\
\hline Factor 3 & 0.68 & & & \\
\hline 29. It is important for me that others think that I am competent and fit. & & 0.76 & 0.61 & Perf-appr \\
\hline 1. An important goal for me when I exercise is to do better than other people. & & 0.60 & 0.42 & Perf-appr \\
\hline 22. It feels really good if I manage to show others that I am really fit. & & 0.53 & 0.48 & Perf-appr \\
\hline \multicolumn{5}{|c|}{ Reduced four-dimensional model ( $71.5 \%$ of variance explained), goodness-of-fit $\chi^{2} / d f=16.5 / 11, p=0.123$} \\
\hline Factor 1 & 0.87 & & & \\
\hline 28. Getting good results is important for me. & & 0.89 & 0.78 & Mast-ext \\
\hline 4. An important goal for me is to get good results in sports. & & 0.78 & 0.78 & Mast-ext \\
\hline 34. My goal is to do well in training. & & 0.71 & 0.71 & Mast-ext \\
\hline Factor 2 & 0.87 & & & \\
\hline 16. I try to avoid situations in training in which I might fail or make mistakes. & & 0.85 & 0.77 & Perf-avo \\
\hline 9. I try to avoid situations in training in which I might look less fit or weak. & & 0.82 & 0.75 & Perf-avo \\
\hline 24. It is important for me not to fail in front of other people when I exercise. & & 0.73 & 0.71 & Perf-avo \\
\hline Factor 3 & 0.89 & & & \\
\hline 11. I train to improve and develop my fitness level. & & 0.93 & $0.81^{\star}$ & Mast-int \\
\hline 17. To develop is an important goal for me in my training. & & 0.75 & $0.81^{*}$ & Mast-int \\
\hline Factor 4 & 0.70 & & & \\
\hline 29. It is important for me that others think that I am competent and fit. & & 0.76 & $0.54^{\star}$ & Perf-appr \\
\hline 22. It feels really good if I manage to show others that I am really fit. & & 0.58 & $0.54^{\star}$ & Perf-appr \\
\hline
\end{tabular}

Notes:

Maximum likelihood with varimax rotation.

*As these factors include only two items, the corrected item-total correlation should be interpreted with caution.

$\lambda$, factor loading; $r_{\text {cit }}$, corrected item-total correlation; mast-int, mastery-intrinsic orientation; mast-ext, mastery-extrinsic orientation; perf-appr, performance-approach orientation; perf-avo, performance-avoidance orientation.

\subsection{Confirmatory factor analyses}

The proposed models were tested for structural validity using confirmatory factor analysis. In the measurement model and consequent test models, each factor was specified to predict corresponding items, and initially the error terms of items were uncorrelated. Chi-square statistics, comparative fit index (CFI, cut-off value $>0.95$ ), and standardized root-mean-square residual (SRMR, cut-off value $<0.08)$ were used to evaluate model fit following the two-index strategy proposed by $\mathrm{Hu}$ and Bentler (1998, 1999) for smallish samples. These indices are recommended instead of, e.g. root-mean-square error of approximation (RMSEA). which tends to indicate falsely poor fit for small samples (refer also Kenny et al. 2015).
First, the measurement model, i.e. the proposed four-dimensional model with original item assignment, was tested. Second, the two-dimensional model with combined mastery and performance scales was tested. Third, the three-dimensional model with mastery-intrinsic, performance-approach and performance-avoidance scales was tested, and finally, the reduced four-dimensional model with the additional mastery-extrinsic scale was tested.

Within each model, first, one minor modification was needed to the proposed model (i.e. freeing the error covariance between one pair of similarly worded items of the mastery-intrinsic orientation scale). Second, regarding the two-dimensional model, one more similar modification was necessary (in two items of the performance-approach scale). Results indicate that the most acceptable fit 
Tab. 2: Goodness-of-fit criteria for the compared models.

\begin{tabular}{lrll}
\hline Model & \multicolumn{1}{l}{$\mathrm{X}^{2}(\mathbf{d f})$} & $\mathrm{CFI}$ & SRMR \\
\hline Measurement (four-dimensional) & $156.8(48)$ & 0.83 & 0.095 \\
Modified measurement $^{1}$ & $100.2(47)$ & 0.94 & 0.079 \\
Two-dimensional $^{2}$ & $218.2(43)$ & 0.80 & 0.122 \\
Modified two-dimensional $^{3}$ & $102.3(51)$ & 0.93 & 0.108 \\
Three-dimensional $^{4}$ & $64.9(24)$ & 0.93 & 0.085 \\
Modified three-dimensional $^{5}$ & $52.15(23)$ & 0.95 & 0.075 \\
Reduced four-dimensional $^{6}$ & $153.31(32)$ & 0.84 & 0.075 \\
Modified and reduced $^{\text {four-dimensional }}$ & $57.05(31)$ & 0.96 & 0.054 \\
\hline
\end{tabular}

Notes:

Definitions for modifications of models are as follows:

${ }^{1}$ The error covariance between one pair of similarly worded items was freed.

${ }^{2}$ Combined mastery and performance dimensions.

${ }^{3}$ The error covariance between two pairs of similarly worded items was freed.

${ }^{4}$ Mastery-extrinsic orientation excluded.

${ }^{5}$ The error covariance between one pair of similarly worded items was freed.

${ }^{6}$ Excluded one item from mastery-intrinsic and performanceapproach dimensions.

${ }^{7}$ The error covariance between one pair of similarly worded items was freed.

$\mathrm{CFI}$, comparative fit index; SRMR, standardized root-mean-square residual.

was achieved with the three-dimensional and reduced four-dimensional models, as the cut-off values were met. Goodness-of-fit criteria are reported in Table 2.

Following these three-factor solutions, items were then used to construct composite variables for further examination. These scales were labelled based on the contents of the items and the original scales as follows: (i) two-dimensional solution: 2Dmastery orientation (Factor 1, six items) and 2Dperformance orientation (Factor 2, five items); (ii) three-dimensional solution: 3Dmastery-intrinsic orientation (Factor 2, three items), 3Dperformance-approach orientation (Factor 3, three items) and 3Dperformanceavoidance orientation (Factor 1, three items) and (iii) reduced four-dimensional solution: R4Dmastery-intrinsic orientation (Factor 3, two items), R4Dmastery-extrinsic orientation (Factor 1, three items), R4Dperformance-approach orientation (Factor 4, two items) and R4Dperformance-avoidance orientation (Factor 2, three items).

\subsection{Correlation results}

In terms of the relations between variables (Table 3), first, the two dimensions of the two-factor model did not correlate with each other. For the three-factor model, the 3Dmastery-intrinsic orientation and 3Dperformanceapproach orientation were positively correlated, as were the two 3Dperformance orientations. With respect to the reduced four-factor model, the two R4Dperformance orientations were again correlated but more strongly than in the 3D model. The two R4Dmastery orientations had differential correlation pattern: the R4Dmastery-intrinsic orientation correlated with R4Dmastery-extrinsic orientation but was not related to the two performance orientation factor, whereas the R4Dmastery-extrinsic orientation was positively correlated with R4Dperformance-approach orientation. This suggests that the partition of the mastery

Tab. 3: Zero-order correlations and descriptive statistics.

\begin{tabular}{|c|c|c|c|c|c|c|}
\hline & M & SD & 1 & 2 & 3 & 4 \\
\hline \multicolumn{7}{|l|}{ Two-dimensional solution } \\
\hline 1. 2Dmastery orientation & 5.92 & 0.94 & - & & & - \\
\hline 2. 2Dperformance orientation & 3.52 & 1.14 & 0.13 & - & & \\
\hline \multicolumn{7}{|l|}{ Three-dimensional solution } \\
\hline 1. 3Dmastery-intrinsic orientation & 6.23 & 0.85 & - & & & \\
\hline 2. 3Dperformance-approach orientation & 4.35 & 1.30 & $0.32^{\star \star \star}$ & - & & \\
\hline 3. 3Dperformance-avoidance orientation & 2.70 & 1.29 & -0.08 & $0.36^{\star \star \star}$ & - & \\
\hline \multicolumn{7}{|l|}{ Reduced four-dimensional solution } \\
\hline 1. R4Dmastery-intrinsic orientation & 6.46 & 0.82 & - & & & \\
\hline 2. R4Dmastery-extrinsic orientation & 5.61 & 1.20 & $0.54^{\star \star \star}$ & - & & \\
\hline 3. R4Dperformance-approach orientation & 4.74 & 1.41 & 0.16 & $0.34^{\star \star \star}$ & - & \\
\hline 4. R4Dperformance-avoidance orientation & 2.70 & 1.29 & -0.15 & -0.02 & $0.45^{\star \star \star}$ & - \\
\hline
\end{tabular}

Notes:

${ }^{*} p<0.05,{ }^{* *} p<0.01$ and ${ }^{* \star *} p<0.001$.

2D/3D, two-/three-dimensional; R4D, reduced four-dimensional. 
and performance dimensions into two components potentially reveals significant relationships that aggregating them might mask. The patterns of correlations are consistent with those in prior studies (Tuominen-Soini et al. 2012; Pulkka and Niemivirta 2013; Tapola et al. 2014).

With respect to descriptive statistics, the masteryintrinsic orientation had the highest mean, followed by mastery-extrinsic orientation (in the R4D model) and performance orientations, in which the approach dimension had a higher mean. Moreover, the performance-approach orientation and performance-avoidance orientation had significantly different mean levels. This was also observed for the two differentiated mastery dimensions, although not as clearly.

\section{Discussion}

In this study, the adaptation of an instrument designed to tap adult students' achievement goal orientations in physical exercise is reported. Based on the analyses, factorial structures relevant to prior research and theoretical assumptions were compared. The contents of the scales, the model fit and structural features of different models supported the validity of the four-dimensional instrumentation that was proposed. However, given that a minor modification, in terms of freeing the error covariance between one pair of similarly worded items, was necessary, results are to be interpreted with a degree of caution. First, in the exploratory factor analysis, it was found that including all the items and based on eigenvalues only, support was displayed for two dimensions only, reflecting original task vs. ego differentiation. However, additional test of fit indicated that this structure did not correspond to the data very well. It is also to be noted that the smallish sample size, and the ensuing low statistical power, may have made the expected dimensions harder to extract. With respect to confirmatory factor analysis, the fit of the two-factor model was found to be unacceptable.

Second, the three-factor model met most of the criteria for structural validity, but the psychometrics still indicated that at least for these data, the structure was not ideal at the statistical level. Variable relations were meaningful and logical, as well as corresponding well to what is known about the associations between different goal orientations. Independently, the evidence concerning this solution also indicates that the proposed three scales, namely, mastery (intrinsic), performance approach and performance avoidance, were successfully converted into the context of physical training.
Third, with respect to the reduced four-factor model, a normal iterative process was conducted and the resulting model, although slightly narrower in terms of the number of items, corresponded quite well to the proposed scales and had thus theoretical relevance. This model actually fit the data better than the actually exploratory two-factor and three-factor models. The results from confirmatory factor analysis also supported the four-factor model, as the criteria for good fit were met with acceptance of one pair of correlated error terms.

In comparison, then, the results suggested that the two-dimensional model did not represent a valid operationalization of motivational goal orientations for these data, but that the further differentiation of both performance dimensions and mastery dimensions into theoretically and empirically supported components were valid steps in this context. Reduction and minor modification of the four-factor model more likely reflect the need to revise the wording of some of the items rather than theoretical inconsistencies in the instrumentation. Thus, it is argued that the proposed four dimensions represent the goal preferences more comprehensively than would be the case if the instrumentation were based on two merged scales or on a more traditional three-dimensional model. Results also suggest that the goal orientation instrument was sensitive to an adequate degree to differentiate, given the modification, between the respective two dimensions of both mastery and performance goal preferences.

The relations between the scales were logical and quite consistent with the results in prior research (e.g. Tuominen-Soini et al. 2012; Pulkka and Niemivirta 2013; Tapola et al. 2014), although it is interesting that the mastery-intrinsic orientation was not associated with the performance-approach orientation, indicating that purposes of developing were not at all related to outperforming others in this context. In addition, slightly different patterns of associations for mastery-intrinsic and mastery-extrinsic orientations were observed. This is taken as evidence of the independence of these two constructs. Based on the mean levels, students' motivation in physical training appears quite adaptive; mostly, they seem to strive for personal development in fitness, as well as for good results. Nevertheless, they recognize social comparison to some extent, which is understandable, considering the competitive ethos at the NDU, but they have very little concerns of failure or appearing inferior.

Altogether, this study confirms that the modification and rewording of the original items were quite successful, as well as being both theoretically relevant and methodologically sound. Furthermore, this study also testifies that the original instrument rightly taps goal orientations in 
such a clear and definite way that they can be adapted to any specific field. However, findings must be reflected upon with some caution, as the study is based on a smallish and special sample. First, regarding the comparison of parallel models, the relatively small sample size and consequently low statistical power, may have affected some fit indices. Second, the physical fitness levels required in the military profession are well defined and well known. Students at the NDU are regularly tested, and physiological screening is part of student selection. Based on this, it is obvious that the participants of this study do exercise regularly and, thus, probably have goals or are at least able to assess them when asked to. A more common population is more likely to include people who do not train, at least not systematically, and thus their assessments of personal goals might not appear as consistent. It has been proposed that the dimensionality of goals in the physical domain may vary according to age, gender and the nature of activity that is referenced (Chi and Duda 1995; Duda and Whitehead 1998).

Finally, with reference to the generalizability of these results, it is to be noted that in this study, the focus was on goal orientations and the applicability of certain dimensions. Therefore, the findings do not necessarily cover all the relevant aims that represent what people actually strive for in their physical exercise. Moreover, the proposed structure on which the composite goal orientation variables were based on included some slight deviations from the expected relations at the item level. It is recommended that in future research, the scales and items are possibly refined in terms of some details and that the results are carefully put into contextual perspective. Future steps in this project are the testing and validation of this instrument on larger and more common samples.

\section{References}

Ames, C. (1992). Classrooms: Goals, structures, and student motivation. Journal of Educational Psychology, 84(3), pp. 261-271.

Ames, C., \& Archer, J. (1987). Mothers' beliefs about the role of ability and effort in school learning. Journal of Educational Psychology, 79(4), pp. 409-414.

Ames, C., \& Archer, J. (1988). Achievement goals in the classroom: Students' learning strategies and motivation processes. Journal of Educational Psychology, 80(3), pp. 260-267.

Attenweiler, W. J., \& Moore, D. (2006) Goal orientations, two, three, or more factors. Educational and Psychological Measurement, 66(2), pp. 342-352.

Button, S. B., Mathieu, J. E., \& Zajac, D. W. (1996). Goal orientation in organizational research: A Conceptual and empirical foundation. Organizational Behavior and Human Processes, 67(1), pp. 26-48.
Chi, L., \& Duda, J. L. (1995). Multi-sample confirmatory factor analysis of the task and ego orientation in sport questionnaire. Research Quarterly for Exercise and Sport, 66(2), pp. 91-98.

Duda, J. L. (1989). Relationship between task and ego orientation and the perceived purpose of sport among high school athletes. Journal of Sport and Exercise Psychology, 11, pp. 318-335.

Duda, J.L. (1992). Motivation in sport settings: A goal perspective analysis. In: Roberts, G.C. (ed.) Motivation in sport and exercise. Human Kinetics, Champaign, IL, pp. 57-91.

Duda, J. L. (1994). A goal perspective theory of meaning and motivation in sport. In: Serpa, S., Alves, J., \& Pataco, V. (eds.) International Perspectives on Sport and Exercise Psychology. Fitness Information Technology, Inc., Morgantown, WV, pp. 127-147.

Duda, J. L., \& Nicholls, J. G. (1992). Dimensions of achievement motivation in schoolwork and sport. Journal of Educational Psychology, 84(3), pp. 290-299.

Duda, J., \& Whitehead, J. (1998). Measurement of goal perspective in the physical domain. In: Duda, J. L. (ed.) Advances in Sport and Psychology Measurement. Fitness Information Technology, Inc., Morgantown, WV, pp. 21-48.

Dweck, C. S. (1986). Motivational processes affecting learning. American Psychologist, 41(10), pp. 1040-1048.

Dweck, C. S. (1992). The study of goals in psychology. Psychological Science, 3(3), pp. 165-167.

Dweck, C. S., \& Elliot, E. S. (1983). Achievement motivation. In: Mussen, P. (gen.ed.), \& Hetherington, E. (vol.ed.), Handbook of Child Psychology. Socialization, Personality, and Social Development, Vol. IV. John Wiley \& Sons, New York, NY, pp. 643-692.

Elliot, A. J. (2005). A conceptual history of the achievement goal construct. In: Elliot, A. J., \& Dweck, C. S. (eds.) Handbook of Competence and Motivation. The Guilford Press, New York, NY, pp. 52-72.

Elliot, A. J., \& Harackiewicz, J. M. (1996). Approach and avoidance achievement goals and intrinsic motivation: A mediational analysis. Journal of Personality and Social Psychology, 70(3), pp. 461-475.

Elliot, A. J., \& McGregor, H. (2001). A 2×2 achievement goal framework. Journal of Personality and Social Psychology, 80(3), pp. 501-519.

Elliot, A. J., Murayama, K., \& Pekrun, R. (2011). A 3×2 achievement goal model. Journal of Educational Psychology, 103(3), pp. 632-648.

Grant, H., \& Dweck, C. S. (2003). Clarifying achievement goals and their impact. Journal of Personality and Social Psychology, 85(3), pp. 541-553.

Hu, L., \& Bentler, P. M. (1998). Fit indices in covariance structure modelling: Sensitivity to underparameterized model misspecification. Psychological Methods, 3(4), pp. 424-453.

Hu, L., \& Bentler, P. M. (1999). Cutoff criteria for fit indexes in covariance structure analysis: Conventional criteria versus new alternatives. Structural Equation Modeling, 6, pp. 1-55.

Hulleman, C. S., Schrager, S. M., Bodmann, S. M., \& Harackiewicz, J. M. (2010). A meta-analytical review of achievement goal measures: Different labels for the same constructs or different constructs with similar labels? Psychological Bulletin, 136(3), pp. $422-449$.

Jagacinski, C. M., \& Duda, J. L. (2001). A comparative analysis of contemporary achievement goal orientation measures. Educational and Psychological Measurement, 61(6), pp. 1013-1039. 
Kaplan, A., \& Maehr, M. L. (2007). The contributions and prospects of goal orientation theory. Educational Psychology Review, 19, pp. 141-184.

Kenny, D. A., Kaniskan, B., \& McCoach, D. B. (2015). The performance of RMSEA in models with small degrees of freedom. Sociological Methods \& Research, 44(3), pp. 486-507.

Kilpatrick, M., Bartholomew, J., \& Riemer, H. (2003). The measurement of goal orientations in exercise. Journal of Sport Behavior, 26(2), pp. 121-136.

Maehr, M. L., \& Zusho, A. (2009). Achievement goal theory: The past, present, and future. In: Wentzel, K. R., \& Wigfield, A. (eds.), Handbook of Motivation in School. Taylor Francis, New York, pp. 77-104.

Middleton, M. J., \& Midgley, C. (1997). Avoiding the demonstration of lack of ability: An underexplored aspect of goal theory. Journal of Educational Psychology, 89(4), pp. 710-718.

Muthén, L. K., \& Muthén, B. O. (1998-2009). Mplus User's Guide, 5th ed. Muthén \& Muthén, Los Angeles, CA.

Nicholls, J. G. (1984). Achievement motivation: Conceptions of ability, subjective experience, task choice, and performance. Psychological Review, 91(3), pp. 328-346.

Nicholls, J. G. (1989). The Competitive Ethos and Democratic Education. Harvard University Press, Cambridge, MA.

Nicholls, J. G., Cheung, P. C., Lauer, J., \& Pataschnick, M. (1989). Individual differences in academic motivation: Perceived ability, goals, beliefs, and values. Learning and Individual Differences, 1, pp. 63-84.

Niemivirta, M. (2002). Motivation and performance in context: The influence of goal orientations and instructional setting on situational appraisal and task performance. Psychologia, 45, pp. 250-270.

Papaioannou, A. G., Zourbanos, N., Krommidas, C., \& Ampatzoglou, G. (2012). The place of achievement goals in the social context of sport: A comparison of Nicholls' and Elliot's models. In: Roberts, G. C., \& Treasure, D. C. (eds.). Advances in Motivation in Sport and Exercise. Human Kinetics, Champaign, IL, pp. 59-90.

Pintrich, P. R. (2000). Multiple goals, multiple pathways: The role of goal orientation in learning and achievement. Journal of Educational Psychology, 92(3), pp. 544-555.

Pintrich, P. R. (2003). A motivational science perspective on the role of student motivation in learning and teaching contexts. Journal of Educational Psychology, 95(4), pp. 667-686.

Pulkka, A.-T., \& Niemivirta, M. (2013). Adult students' achievement goal orientations and evaluations of the learning environment: A person-centred longitudinal analysis. Educational Research and Evaluation, 19(4), pp. 297-322.

Shen, B., Chen, A., \& Guan, J. (2007). Using achievement goals and interest to predict learning in physical education. Journal of Experimental Education, 75(2), pp. 89-108.

Shen, B., McCaughtry, N., Martin, J. J., \& Fahlman, M. (2009). Motivational profiles and their associations with achievement outcomes. Journal of Teaching in Physical Education, 28, pp. 441-460.
Skaalvik, E. M. (1997). Self-enhancing and self-defeating ego orientation: Relation with task and avoidance orientation, achievement, self-perceptions, and anxiety. Journal of Educational Psychology, 89(1), pp. 71-81.

Tapola, A., Jaakkola, T., \& Niemivirta, M. (2014). The influence of achievement goal orientations and task concreteness on situational interest. Journal of Experimental Education, 82(4), pp. 455-479.

Tapola, A., Veermans, M., \& Niemivirta, M. (2013). Predictors and outcomes of situational interest during a science learning task. Instructional Science, 41(6), pp 1047-1064.

Tuominen-Soini, H., Salmela-Aro, K., \& Niemivirta, M. (2008). Achievement goal orientations and well-being: A personcentred analysis. Learning and Instruction, 18(3), pp. 251-266.

Tuominen-Soini, H., Salmela-Aro, K., \& Niemivirta, M. (2011). Stability and change in achievement goal orientations: A person-centred approach. Contemporary Educational Psychology, 36(2), pp. 82-100.

Tuominen-Soini, H., Salmela-Aro, K., \& Niemivirta, M. (2012). Achievement goal orientations and academic well-being across the transition to upper secondary education. Learning and Individual Differences, 22(3), pp. 290-305.

Urdan, T. (1997). Achievement goal theory: Past results, future directions. In: Maehr, M., \& Pintrich, P. (eds.). Advances in Motivation and Achievement, Vol. 10. JAI Press, Greenwich, CT, pp. 99-141.

Vandewalle, D. (1997). Development and validation of a work domain goal orientation instrument. Educational and Psychological Measurement, 57(6), pp. 995-1015.

Wang, C. K. J., Biddle, S. J. H., \& Elliot, A. J. (2007). The $2 \times 2$ achievement goal framework in physical education context. Psychology of Sport and Exercise, 8(2), pp. 147-168.

Wigfield, A., \& Cambria, J. (2010). Students' achievement values, goal orientations, and interest: Definitions, development, and relations to achievement outcomes. Developmental Review, 30(1), pp. 1-35.

Zweig, D., \& Webster, J. (2004). Validation of a multidimensional measure of goal orientation. Canadian Journal of Behavioural Science, 36(3), pp. 232-243.

\section{Bionote}

\section{Antti-Tuomas Pulkka, Major, PhD (education)}

Currently a lecturer at the Department of Leadership and Military Pedagogy, National Defence University, Helsinki, Finland. His research interests include motivation in learning, well-being and learning environments. 